\title{
DRAFT GUIDELINES FOR THE ALLOCATION OF PUBLIC LOGISTICS CENTRES OF INTERNATIONAL IMPORTANCE
}

This paper deals with the design of methodology for the allocation of public logistics centres (VLC) of international importance in the Slovak Republic. The decision on the location of the logistics centre can be seen as a decision problem; for this type of task the multi-criteria analysis method is used. The first part of the paper (except introduction) includes a description of the general procedure for multi-criteria assessment of the variants. The second part presents the identification of the variants and the establishment of the evaluation criteria. The third part of the paper provides an identification of appropriate methods for a given type of task. The last part of the contribution presents the creation of a criteria matrix and the determination of prioritizing variants using the method of weighted sum, the weights being determined on the basis of Saaty's pairwise comparison method.

Keywords: Public logistics centre, multi-criteria analysis, SAATY method, weighted sum analysis.

\section{Introduction}

Multi-criteria decision making theory is based on mathematical modelling. Mastering the basic multi-criteria optimization techniques can be done with very simple mathematics [1].

The decision means in a given situation choosing one option from a list of potentially viable variants against a large number of criteria. Next to the list of criteria indirectly forming the objective of the decision analysis it is necessary to have a list of variants from which to choose. Cases where a clearly defined list of potential variants is available are more or less the exception than the rule. This list can be explicitly specified as the sum of a finite number of options, or implicitly specify the conditions that are considered acceptable and with which the decision options must comply. Even at this stage of the decision-making process it is generally difficult to avoid subjective influences, having to finding out experts' opinion or that of the customer [2].

\section{General multi-criteria evaluation of variants}

In order to standardize, define and select methods of evaluation for multi-criteria evaluation of variants which support decision making, it is necessary to know the following [3]:

- what is to be decided,

- what goals are to be met (what objectives are to be achieved and under what conditions),
- aspects of what is to be decided (what aspects the decisionmaking process must comply with)

- the time line for the outcome of the decision making process. The general procedure for the multi-criteria evaluation of variants involves six relatively distinct steps - identification of variants, establishment of a set of criteria, determination of criteria weightings, determination of criterion examples, partial evaluation of variants, selecting the most suitable variant [4].

The general procedure for multi-criteria evaluation of variants as an integral part of a multi-criteria decision-making process of variants assumes that there are at least two possible variants as solutions for the issue [5].

In the paper, we decided that the process of multi-criteria evaluation of variants would be adjusted to include 4 key points: identification of variants, establishment of a set of criteria, determination of criteria weightings and the selection of the most suitable variant.

\section{Identification of variants and establishment of set of criteria}

\section{Identification of variants}

In stage one it is necessary to identify a set of variants from which the final solution will be chosen. The regions of Slovakia where the Public Logistics Centres (VLC) of international

\footnotetext{
* ${ }^{1}$ Ondrej Stopka, ${ }^{1}$ Rudolf Kampf, ${ }^{1}$ Jiri Kolar, ${ }^{2}$ Iveta Kubasakova, ${ }^{3}$ Christopher Savage

${ }^{1}$ Institute of Technology and Business in Ceske Budejovice, Czech Republic

${ }^{2}$ Department of Road and Urban Transport, Faculty of Operation and Economics of Transport and Communications, University of Zilina, Slovakia

${ }^{3}$ Christopher Savage. Polytechnic of Namibia, Deputy Director, Namibian German Centre for Logistics, Windhoek, Namibia

E-mail: ondrej.stopka@fpedas.uniza.sk
} 
importance should potentially be placed were identified as those of: Bratislava, Trnava, Trencin, Nitra, Zilina, Banska Bystrica, Presov and Kosice.

\section{Establishment of a set of criteria}

Stage two of the process of multi-criteria analysis involves establishing a set of criteria which influence the process of decision making in the selection of variants. [6].

Developing a tailor-made system of evaluation criteria is an important step in the whole multi-criteria analysis process, one which can significantly affect the overall outcome of the evaluation. The rational formation of evaluation criteria significantly depends on a thorough knowledge of the object of evaluation and on a systemic understanding of its structure and its functions. The set of criteria must be comprehensive i.e. it must reflect the essential characteristics of the objects (variants). If the latter is not the case, a gross distortion in the results may occur [6], [7] and [8].
After determining the objectives of the analysis of available knowledge, relevant to this article, 10 criteria primarily from socio-economic areas were defined. For these criteria critical data were obtained based on the study of the functions and perspectives that are related to the activities carried out in a VLC. Due to the prerequisite that all the data (associated with different factors) should be related to the same time period, only data collected for 2010 appears in this article [7].

For clarity, the criteria (factors) are summarized in the following Table 1. Table 2 shows the specific values of criteria related to individual variants (regions in the SR).

\section{Identification of crucial methods used for the design} of methodology of allocating public logistics centres

Proposing the placement of VLC can be viewed as a decision problem in which the final decision is influenced by a group of external factors. For the purpose of solving decision making

Overview of criteria related to the solution of the problem of allocating VLC of international importance

Table 1

\begin{tabular}{|l|c|}
\hline Criteria & Acronym (designation) \\
\hline GDP per capita (PPS) & GDP \\
\hline Average GDP growth over 5 years & GDPGR \\
\hline Value of direct foreign investment (EUR thousands) & FDI \\
\hline Amount of transported goods via public roads (thousands tonnes) & NGR \\
\hline Number of large companies (> 250 employees) & NSME \\
\hline Number of small and medium size companies (<250 employees) & NP \\
\hline Population size & AGW \\
\hline Average gross monthly wage (EUR) & RN \\
\hline State of road network $(k m)$ & AGTC \\
\hline Regional connections with network of railway lines AGTC & \\
\hline
\end{tabular}

Source: authors

Actual values of criteria related to individual variants

Table 2

\begin{tabular}{|l|l|l|l|l|l|l|l|l|l|l|}
\hline Variant & GDP & GDPGR & FDI & TGR & NBE & NSME & NP & AGW & RN & AGTC \\
\hline Bratislava region & 43063 & 1.055 & 25182386 & 8255 & 180 & 49420 & 628686 & 991 & 241.75 & 3 \\
\hline Trnava region & 20078 & 1.067 & 3109697 & 5651 & 61 & 13136 & 563081 & 705 & 360.87 & 3 \\
\hline Trencin region & 15823 & 1.057 & 1803931 & 8921 & 73 & 11781 & 598819 & 657 & 508.52 & 2 \\
\hline Nitra region & 14841 & 1.044 & 1552909 & 2875 & 51 & 14301 & 704752 & 636 & 517.99 & 2 \\
\hline Zilina region & 15826 & 1.072 & 2283702 & 4320 & 61 & 13390 & 698274 & 686 & 593.54 & 2 \\
\hline $\begin{array}{l}\text { Banska Bystrica } \\
\text { region }\end{array}$ & 13215 & 1.062 & 816171 & 3968 & 48 & 12525 & 652218 & 635 & 733.89 & 0 \\
\hline Presov region & 10104 & 1.041 & 415900 & 4258 & 58 & 13120 & 809443 & 594 & 715.43 & 2 \\
\hline Kosice region & 14109 & 1.047 & 2500399 & 6369 & 52 & 14744 & 780000 & 716 & 371.88 & 2 \\
\hline
\end{tabular}

Source: [9] - [11] 
problems the methods of multi-criteria analysis are used and these methods can therefore be used in deciding the location of VLC.

There are many different methods of multi-criteria analysis which can help in the allocation of VLC. In practice, however, many methods cannot be used because they do not allow for the processing of all the intricacies [4] and [5].

On this basis it was decided to use the weighted sum method - WSA, which appears to be relatively easy to handle and easy to apply to the complex and difficult task of allocating VLC. The weighted sum method requires cardinal information, criteria matrix $Y$ and a vector of criteria weightings $v$. It constructs the overall rating for each variant and so it can be used for finding one of the most appropriate variants as well as for arranging variants on a scale from the best to the worst.

In its calculation the Weighted Sum Analysis method uses criteria with set weights. Again, there are several methods to determine the criteria weights. For the purposes of this article the Saaty pairwise comparison method was chosen [4].

This is a method of quantitative pairwise comparison of criteria. For the evaluation of paired comparison of criteria, a 9 point scale is used. It is also possible to use intermediate values (2, $4,6,8)$. The researcher compares each pair of criteria and enters the sizes of preferences of $i$-thin relation to the $j$-th criterion in the Saaty matrix. In case $j$-th criterion is preferred above that of the $i$-th criterion, inverse values are entered into the Saaty matrix $(s i j=1 / 3$ for low preference, $s i j=1 / 5$ for strong preference, etc.) [12].

\section{Setting up criteria matrix and ranking of variants}

In the theory of Multiple Criteria Decision Making we work with a general number of criteria $k$ and with a general number of $p$. The value achieved by variant $i$ for $j$-th criterion is labelled as $y_{i j}$ and is called the criterion value. The next step is to arrange these values into a matrix which we call the criteria matrix. The rows of the criteria matrix are formed by the individual variants. The columns of the criteria matrix correspond with the individual criteria.

In our case the criteria matrix is identical to Table 2.

a) Transfer of criteria to the same type

For the purposes of tasks related to the criteria matrix it is appropriate that all the criteria are of the same type (minimization or maximization). Transfer of the criteria to the same type is not difficult because each minimization criterion can be easily converted to maximization criterion [4]. In our case it is necessary to perform a modification in the initial criteria matrix at the eighth criterion, that of average monthly wage. For average wage the highest value is EUR 991, the transformation will replace the original criteria value $y_{i 8}$ with the value $991-y_{i 8}$.

b) Ideal and basal variant

Ideal variant is the best option which can be theoretically or practically achieved.

Basal variant is the worst variant which can be theoretically or practically achieved.

c) Normalization of criteria matrix

If we know the ideal and basal variants, we simply normalize the criteria matrix. All values in the criteria matrix will be in the interval $\langle 0,1\rangle$, the ideal value of the criteria matrix will then be represented by the number 1 and the basal by the number 0 . An important feature of this normalized criteria matrix is that it is completely independent of the units [4].

If we mark the basal value for criteria $j$ as $D_{j}$ and the ideal value for criteria $j$ as $H_{j}$ then the normalized criteria matrix $\left(r_{i j}\right)$ arises from the initial criteria matrix $\left(y_{i j}\right)$ as follows:

$$
r_{i j}=\frac{y_{i j}-D_{j}}{H_{j}-D_{j}} .
$$

According to the above formulae we set up the required matrix (Table 3):

Normalized criteria matrix

Table 3

\begin{tabular}{|l|l|l|l|l|l|l|l|l|l|l|}
\hline $\begin{array}{l}\text { Criterion } \\
\text { Variant }\end{array}$ & GDP & GDPGR & FDI & TGR & NBE & NSME & NP & AGW & RN & AGTC \\
\hline Bratislava & 1 & 0.4516 & 1 & 0.8898 & 1 & 1 & 0.2663 & 0 & 0 & 1 \\
\hline Trnava & 0.3026 & 0.8387 & 0.1088 & 0.4591 & 0.0985 & 0.036 & 0 & 0.7204 & 0.242 & 1 \\
\hline Trencin & 0.1735 & 0.5161 & 0.056 & 1 & 0.1894 & 0 & 0.1451 & 0.8413 & 0.5421 & 0.6667 \\
\hline Nitra & 0.1437 & 0.0968 & 0.0459 & 0 & 0.0227 & 0.067 & 0.5751 & 0.8942 & 0.5613 & 0.6667 \\
\hline Zilina & 0.1736 & 1 & 0.0754 & 0.239 & 0.0985 & 0.0427 & 0.5488 & 0.7683 & 0.7148 & 0.6667 \\
\hline Banska Bystrica & 0.0944 & 0.6774 & 0.0162 & 0.1808 & 0 & 0.012 & 0.3618 & 0.8967 & 1 & 0 \\
\hline Presov & 0 & 0 & 0 & 0.2287 & 0.0758 & 0.0356 & 1 & 1 & 0.9625 & 0.6667 \\
\hline Kosice & 0.1215 & 0.1935 & 0.0842 & 0.5779 & 0.0303 & 0.0787 & 0.8805 & 0.6927 & 0.2644 & 0.6667 \\
\hline
\end{tabular}

Source: authors 
d) Determination of criteria weightings

As mentioned above, the determination of criteria weightings will be made using the Saaty pairwise comparison method. The first step of the Saaty method is to determine the relationship between each pair of criteria when the level of significance (preference) is determined in a spot range between 1-9. This is determined as follows [4] and [13]:

To ensure the greatest possible objectivity in the allocation methodology for the allocation of VLC, five members of the research team (a team was formed for the purpose of solving the tasks in the post) were asked to determine preferences between individual criteria. Each of the five members of the team set a level of significance for each pair of criteria. For each element of the matrix a sum of the sub-matrices of all members of the team was established and then the average was calculated.

Table 4 contains the individual values obtained from a procedure of the determination of criteria weightings.
Elements of the Saaty method were used for further calculations. The values obtained for the individual criterion in the intermediate calculations and the final values of the vector of weights of individual criterion are given in Table 5.

From this overview of setting criteria weightings using the Saaty pairwise comparison method it is clear that the highest priority is assigned to the transport infrastructure and also to the transport characteristics of the region. The least important criteria are the number of large state enterprises and the level of direct foreign investment in the region [14] and [15].

e.) Selecting the most suitable variant using the WSA method

1. Calculation of normalized criteria matrix - see Table 3

2. Multiplication of normalized matrix by the vector of weights indicated by Saaty method. Calculation of this procedure is summarized in Table 6.

Resulting Saaty matrix

Table 4

\begin{tabular}{|l|l|l|l|l|l|l|l|l|l|l|l|}
\hline & Criterion & GDP & GDPGR & FDI & TGR & NBE & NSME & NP & AGW & RN & AGTC \\
\hline 1. & GDP (PPS) & 1.00 & 2.00 & 3.00 & 0.33 & 2.00 & 1.00 & 1.00 & 0.50 & 0.33 & 0.50 \\
\hline 2. & GDPGR & 0.50 & 1.00 & 2.00 & 0.20 & 1.00 & 0.50 & 0.50 & 0.25 & 0.20 & 0.25 \\
\hline 3. & FDI (EUR 000) & 0.33 & 0.50 & 1.00 & 0.17 & 1.00 & 0.33 & 0.50 & 0.20 & 0.14 & 0.20 \\
\hline 4. & TGR (tons 000) & 3.00 & 5.00 & 6.00 & 1.00 & 5.00 & 2.00 & 3.00 & 2.00 & 1.00 & 2.00 \\
\hline 5. & NBE & 0.50 & 1.00 & 1.00 & 0.20 & 1.00 & 0.50 & 0.50 & 0.25 & 0.20 & 0.25 \\
\hline 6. & NSME & 1.00 & 2.00 & 3.00 & 0.50 & 2.00 & 1.00 & 1.00 & 0.50 & 0.50 & 0.50 \\
\hline 7. & NP & 1.00 & 2.00 & 2.00 & 0.33 & 2.00 & 1.00 & 1.00 & 0.50 & 0.33 & 0.50 \\
\hline 8. & AGW (EUR) & 2.00 & 4.00 & 5.00 & 0.50 & 4.00 & 2.00 & 2.00 & 1.00 & 0.50 & 1.00 \\
\hline 9. & RN (km) & 3.00 & 5.00 & 7.00 & 1.00 & 5.00 & 2.00 & 3.00 & 2.00 & 1.00 & 2.00 \\
\hline 10. & AGTC & 2.00 & 4.00 & 5.00 & 0.50 & 4.00 & 2.00 & 2.00 & 1.00 & 0.50 & 1.00 \\
\hline
\end{tabular}

Source: authors

Values obtained using the Saaty method

Table 5

\begin{tabular}{|r|l|l|l|l|}
\hline & Criterion & Sum of elements & Tenth square root of sum & Resulting weight of criterion \\
\hline 1. & GDP (PPS) & 0.326700 & 0.894159 & 0.07198 \\
\hline 2. & GDPGR & 0.000625 & 0.478176 & 0.03850 \\
\hline 3. & FDI (EUR 000) & 0.000026 & 0.347934 & 0.02801 \\
\hline 4. & TGR (tons 000) & 10800.000000 & 2.531293 & 0.20378 \\
\hline 5. & NBE & 0.000313 & 0.446226 & 0.03593 \\
\hline 6. & NSME & 0.750000 & 0.971642 & 0.07823 \\
\hline 7. & NP & 0.217800 & 0.858629 & 0.06913 \\
\hline 8. & AGW (EUR) & 160.000000 & 1.661162 & 0.13374 \\
\hline 9. & RN $(\mathrm{km})$ & 12600.000000 & 2.570615 & 0.20696 \\
\hline 10. & AGTC & 160.000000 & 1.661162 & 0.13374 \\
\hline
\end{tabular}

Source: authors 
Intermediate calculation of the order of variants

Table 6

\begin{tabular}{|l|l|l|l|l|l|l|l|l|l|l|}
\hline Variant & Griterion & GDPGR & \multicolumn{1}{|c|}{ FDI } & TGR & NBE & NSME & \multicolumn{1}{|c|}{ NP } & AGW & RN & AGTC \\
\hline Bratislava & 0.07198 & 0.01739 & 0.02801 & 0.18132 & 0.03593 & 0.07823 & 0.01841 & 0 & 0 & 0.13374 \\
\hline Trnava & 0.02178 & 0.03229 & 0.00305 & 0.09356 & 0.00354 & 0.00282 & 0 & 0.09635 & 0.05008 & 0.13374 \\
\hline Trencin & 0.01249 & 0.01987 & 0.00157 & 0.20378 & 0.00681 & 0 & 0.01003 & 0.11251 & 0.11219 & 0.08916 \\
\hline Nitra & 0.01034 & 0.00373 & 0.00129 & 0 & 0.00082 & 0.00524 & 0.03976 & 0.11959 & 0.11617 & 0.08916 \\
\hline Zilina & 0.01250 & 0.03850 & 0.00211 & 0.04870 & 0.00354 & 0.00334 & 0.03794 & 0.10275 & 0.14794 & 0.08916 \\
\hline BanskaBystrica & 0.00679 & 0.02608 & 0.00045 & 0.03684 & 0 & 0.00094 & 0.02501 & 0.11992 & 0.20696 & 0 \\
\hline Presov & 0 & 0 & 0 & 0.04660 & 0.00272 & 0.00278 & 0.06913 & 0.13374 & 0.19920 & 0.08916 \\
\hline Kosice & 0.00874 & 0.00745 & 0.00236 & 0.11776 & 0.00109 & 0.00616 & 0.06087 & 0.09264 & 0.05472 & 0.08916 \\
\hline
\end{tabular}

Source: authors

3. For each of the variants the elements of the matrix for all criteria were counted and placed in descending order whereby the order of variants was identified [16]. The order of variants is shown in Table 7.

Identifying the order of variants

Table 7

\begin{tabular}{|c|c|c|}
\hline Variant & Resulting value & Order of variants \\
\hline Bratislava & 0.56501 & $\mathbf{2 .}$ \\
\hline Trnava & 0.43721 & $\mathbf{6 .}$ \\
\hline Trencin & 0.56841 & $\mathbf{1 .}$ \\
\hline Nitra & 0.38610 & $\mathbf{8 .}$ \\
\hline Zilina & 0.48648 & $\mathbf{4 .}$ \\
\hline BanskaBystrica & 0.42299 & $\mathbf{7 .}$ \\
\hline Presov & 0,54333 & $\mathbf{3 .}$ \\
\hline Kosice & 0.44095 & $\mathbf{5 .}$ \\
\hline
\end{tabular}

Source: authors

\section{Conclusion}

Based on the calculations performed for a decision on the allocation of one VLC of international importance and two other VLCs of regional importance using the weighted sum - WSA (multi-criteria analysis method), using all of the above criteria, the following regions in the following order were selected as suitable variants:

- Trencin Region,

- Bratislava Region,

- Presov Region.

The method allows for the reduction in the number of criteria that are taken into account in search of solutions. Several calculations with different numbers of criteria were made and always with more or less the same result - the first two positions according to the method of weighted sum were always taken by the Bratislava and Trencin regions (or in reverse order).

However, when taking into account the density of the road network and the amount of the average monthly nominal wages in the regions when assessing the variants, the region of Zilina was selected as the third most suitable region instead of Presov. The reason for this change is that for these important criteria the Presov region, compared with other regions, has relatively high values.

\section{Acknowledgement}

This work was part of the project DOPSITReg. No. CZ.1.07/2.3.00/20.0226 funded under the Operational Program Education for Competitiveness.

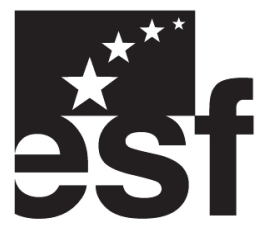

european social fund in the czech republic

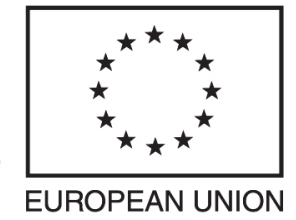

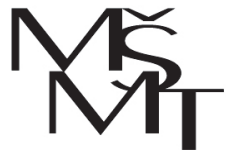

MINISTRY OF EDUCATION YOUTH AND SPORTS

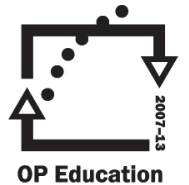

for Competitiveness 


\section{References}

[1] FIALA, P. at al.: Multi-Criteria Decision Making. VSE, Praha, 1994. ISBN 80-70709-748-7.

[2] BROZOVA, H., HOUSKA, M., SUBRT, T.: Models for Multicriteria Decision. Prague: Credit 2003m ISBN 80-213-1019-7.

[3] FOTR, J. et al.: Management Decisions, Procedures, Methods and Tools. Prague, Printer Havlickuv Brod, a. s., 2006. ISBN 80-86929-15-9.

[4] KAlCEVOVA, J.: Study Materials - Multi-Criteria Analysis. [Electronic source]. [Citation 2013-01-21]. 2008. Accessible via: 〈http://jana.kalcev.cz/vyuka/kestazeni/EKO422-KriterialniMatice.pdf〉; 〈http://jana.kalcev.cz/vyuka/kestazeni/EKO422Kardinalni1.pdf>. Study Materials - Methods for Determining Weights of Criteria. [Electronic source]. [Citation 2013-01-21]. 2008. Accessible via: 〈http://jana.kalcev.cz/vyuka/kestazeni/EKO422-Kardinalni1.pdf >.

[5] KLICNAROVA, J.: Multi-Criteria Evaluation of Alternatives - Methods. Faculty of Applied Mathematics and Informatics, University of South Bohemia, Ceske Budejovice, Faculty of Economics. [Electronic source]. [Citation 2013-01-14]. 2010.

[6] TRIANTAPHYlloU, E.: Multi-Criteria Decision Making: A Comparative Study. Dordrecht: Kluwer Academic Publishers, 2000. ISBN 0-7923-6607-7.

[7] TUCNIK, P.: Multiple Criteria Decision Making in Multi-Agent Systems. [Citation 2013-02-20] Accessible via: <http://hilbert.chtf. stuba.sk/KUZV/download/kuzv-tucnik.pdf>.

[8] Institute of Automation and Computer Science - Internet page. Multi-Criteria Decision Making. [Electronic source]. [Citation 201301-23]. 2010. Accessible via: <www.uai.fme.vutbr.cz/ jdvorak/vyuka/osa/Vicekrit.pp>.

[9] Statistical Office of the Slovak Republic - Internet page of National Office for Statistics: Regional GDP 1995 - 2010. [Electronic source]. [Citation 2013-03-02]. 2013. Accessible via: <http://portal.statistics.sk/files/Sekcie/sek_300/330/rev_hdp/reg_rev_ hdp_1995-2010.pdf〉. 〈http://portal.statistics.sk/showdoc.do?index=110\&words=obyv\&docid=108>. 〈http://portal.statistics.sk/ showdoc.do?docid=1724〉. 〈http://portal.statistics.sk/showdoc.do?docid=187〉. 〈http://portal.statistics.sk/files/Sekcie/sek_600/ Demografia/Obyvatelstvo/vyvoj_obyvatelstva_sr/vyvoj-2010.pdf>.

[10] SARIO - Internet page of Slovakian Agency for Development Investment and Commerce: The inflow and outflow of foreign direct investments in 2010. [Electronic source]. [Citation 2013-02-07]. 2009 SARIO. Accessible via: <http://www.sario.sk/?pzi-prilevodlev〉.

[11] Slovak Road Administration - Internet page of Transport Databanks: Summary Data on the Network of Roads. [Electronic source]. [Citation 2013-02-03]. 2013. Accessible via: 〈http://www.cdb.sk/sk/Vystupy-CDB/Statisticke-prehlady/k-1-1-2011.alej〉.

[12] LIZBETIN, J., KLAPITA, V.: Intermodal Transport, 1 edition. Displaced the EDIS Publishing, Zilina University in October 2010. ISBN 978-80-554-0266-6.

[13] SAATY TH. L., VARGAS L. G., WENDELL R. E.: Assessing Attribute Weights by Rations. Omega, Intern. J. of Management Science, 2, No. 1, pp. 9-13, 1983, Priority Setting in Complex Problems. In: Hansen, P.: Essays and Surveys on Multiple Criteria Decision Making. Proc. of the Fifth Intern. Conference on Multiple Criteria Decision Making, Berlin/Heidelberg/New York : Springer-Verlag, pp. 326-336, 1983., Axiomatic Foundation of the Analytic Hierarchy Process in Management Science, 32, No. 7, pp. 841-847, 1986

[14] KALASOVA, A., KRCHOVA, Z.: Analysis of Road Traffic Accident Rate in the Slovak Republic and Possibilities of its Reduction Through Telematic Applications. Transport Systems Telematics: 10 ${ }^{\text {th }}$ conference, TST 2010, Katowice - Ustron, 2010: selected papers - Berlin: Springer - Verlag, 2010. ISBN 978-3-642-16471-2, pp. 463-468 (Communications in computer and information science, pp. 104. ISSN 1865-0929).

[15] SOSEDOVA, J., SULGAN, M., RIEVAJ, V.: European Transport Corridors and Slovakia. Second revised edition. EDIS - Publishing University of Zilina, 2010, ISBN 978-80-554-0255-0.

[16] SOSEDOVA, J., SLESINGER, M., BARIAK, M.: Telematics in Inland Navigation. Communications - Scientific Letters of the University of Zilina, vol. 12, 3/2008, EDIS - ZU Zilina, pp. 66 - 68, ISSN 1335 - 4205. 